\title{
Do you Think with your Frequent Visits by Your Doctors to Prolong Probable your Patient Lives?
}

\author{
Antonín Cuc* \\ Occupational Health and Safety including Medical Devices, Czech Republic
}

Submission: February 24, 2018; Published: April 26, 2018

*Corresponding author: Antonín Cuc, Expert in Cybernetics, Occupational Health and Safety including Medical Devices, Prague, Czech Republic, Email: betruea@gmail.com

\section{Opinion}

The relative frequence of extremal medical mistakes in Diagnostics and so as by the choice of adequated individual patient Treatments are about $10 \%$ for a likehood indivdual unique Doctor's medical activity in Outdoor or Hospital activities, with the tolerancy of statistic reliability $+/-2 \%$ and with statistic defined sure $98 \%$ - by the Results of the international Research The World Health Organisation in all Countries OECD in year 2010. It is similar dangeourous Your intenden Act to visit next week your Physician - it is a similar Hazard like as by the games with Russian Roulletes, there are similar statistic distributions of fatal risky behaviour - as in the sequential steps of risks gave cauntable probabilities There are always lower probable to be still living or to die - it is very funny for idiots, for morbid spectators or for Owners of a Funeral Industry - I regret, for the Orthopady CZ too.

As a Patient CZ, you have no Rights to protest for many times illegal technical medical working of Providers CZ and medical staff, but you have a respect from Physicians only a subject of Materials stream! in the fixed medical Workshops - with similar technical equipments and with similar educated medical staff without the sufficient knowledge's of Technician skills to respect Product in void "CE", recommended technologic user processing, usage Product firm installing instruments, product set of installing firm measurement, false understanding fixed Technician legal conditions by content including the mandatory creating the individual Clinic Plan of surgery always by the Principles in Producer documents "The Certification of Users for Products "CE", etc. There is lack of basal technician knowledge's in the workflow of medical staff, but the Mass of Victims CZ is fully ignored.

\section{Shorten Said}

Our Providers Health care CZ so as medical staff - Physicians CZ hate namely the speaking and some commenting of experienced Patient CZ informed about the duties to legal garance and continual industrial controlling of Technician Quality of usage Medical Devices in a like hood medical workflow, always by the Technician requirements EU/CZ Laws! There are No efficient common Interface from the Results of Clinic Tests of a new Medical Devices "CE" and the real next user praxes of Medical staff, there are always Patient as a potential Mass Victims of Diletant technologic illegal technical processing in frame the Medical processing, there are Mass of the partial repeated fatal illegal medical technical mistakes - which there are dehonesting medical Works by right usage Binary Logics for the Unit of the partial mixed Phenomenons Truth, False. Nearly most of finished Medical processing is FALSE - for evident Mass illegal partial technical activites by usage Medical Devices "CE" in medical workflow CZ, with many needless repeated yearly heavy injured and often casual preliminary dying Patients CZ. Despite you will be coded as a dying Patient lege artis CZ.

You should to come on Patient Visit in Ambulances of Providers Health care CZ - and you should to shoot immediately on your Head with silent with similar Effects! Why the medicine care is organized as the russian roulete about my patient life in orthopady cz? The mortalities or heavy injuring Patient CZ after false Medical Health care are acceptable as medical explanation "self-evident Patient usual risks in medical branches CZ" contrary Technician requirements of EU/CZ Laws vigour for Users Medical care too!

By today's Medical opinion CZ are said - there among individual Patients many small, many big or many well colored People, there fully excluded to be used the Orthopaedic Implants always with full functional technical conditions since the first moment to prove on the surgery hall, from The first functional mandatory testing - only Technicians or manic Patients as the disoriented idiots, they could ask such Technician legal conditions to Industrial continual controlling parameters medical workflow with Technical controlled Quality with similar samplings by the firm recommended partial guaranteed processing in medical implanting processing similar ways and with statistic legal technical parameters of safety and functionalities by a likehood Producers Medical Devices since finished Clinic Testing - so as by similar samplings and parallely comparation from industrial 


\section{Orthopedics and Rheumatology Open Access Journal (OROAJ)}

praxes with Medical Devices of Users - Providers Health care in Hospital net, in Orthopaedic Clinic OECD!

There are in Users praxes organised Mass Medical Confusions and frequential Patients Death -with the official agreement and absolute passivity's of the fatal accepting illegal medical habits with agreements of Criminal Police CZ without a likehood patient support - and with a like hood independent continual industrial supervised the guarances regards to Technician Requirements EU/CZ Laws of Medical Processing - for example: In the Czech republic are yearly realised number of 13 thousands individual prime implantation sets THA, there are actual to used the same principles.

By refreshing similar tests of Criminal Anthropology to controlling the actual legal placement the centric perfect functional anchoring the orthopaedic implants in patient bones in Geometry 3D, with usage exact Biomechanics, etc.. In this moment none of Orthopads CZ, Radiologists CZ, Criminal Anthropologists CZ are continuing in rational legal Dialogs with needless heavy Injured Patients CZ as a official Plaintiffs - including me, when I give to the Judge the Letter with the Criminal technical evidences about many illegal technical and procedural mistakes, false processing qualities of partial technician medical implanting activites contrary fixed mandatory product functionality, contrary Product technologic accuracy by assembling processing, perfect safety timing standard preliminary and post operational RTG imaging with legal rational truthfully interpretation resolutions by the Firm installing radiologic installing Masks of used set Total Hip arthroplasty, with legal respects to mandatory Product accuracy, product functionality, product durability, product safety implanting, prediction of user perfect duration of usage Implants for the Orthopaedic patient, etc. My murders don't understand Czech Language, Czech implanting Laws, Biomechanics, Biostatistics, Binary Logics, Legality, Justify, casual shorten patient Life, etc.

So as we could see parallel apathic agreements with such Mass illegal usage MD of Justice CZ in medical processing, all Victims CZ about 4\% casual mortalities. For Orthopaedic surgeries - they are false coded as "LEGE ARTIS CZ". There is nonsense including accepting. your probable needless exwaitng in forced preliminary Patient Death - and parallel similar ways are accepting false in all State net of The Penalty Offices CZ to ignoring the False biomechanical arguments in Court Medical Messages and with ignoring a supervised Technical illegal medical Mass repeated mistakes - in frequently repeated processing in Technician and Medical Radiology, in usage Geometry 3 D by Diagnostics, in usage comparison of firm installing radiologic Masks, conditions for safety legal planning placement of Implants in individual bones, right timing, technical controlling of partial activites and right sequential ordering the partial medical activities, in Orthopaedic Clinics, there are frequent accepted: Absences of mandatory Clinic Plans in Health documentation of each individual surgeries before beginning the works in Surgery Halls, etc.
There are ignoring probable statistic estimates about of summary probable needless consequents some sort of Mistakes - Number of Mass yearly heavy injured or preliminary casual dying Patients CZ - yearly there are needless about Sum 40 thousands heavy injured Patients CZ preliminary casual dying - including me, all Victims CZ there are coded false "Lege Artis CZ"!

There are no State interests and reasons to renewed the false Civic Court Trials as the Penalty Court Trial for me - with the technician criminal verified technical evidences only - It is the closed and fixed Standpoint of the Main State Penalty Office in Prague CZ, "with arguments: because none of the Technical illegal partial medical activities could have a influences to evaluate the Medical processing or judicial processing different as "Lege artis CZ", because the Providers Health care CZ and medical staff have got never accept no legal responsibilities to work with respect the Technician Requirements of EU/CZ Laws for safety and functional implanting Total Hip Arthroplasty in my body - namely by the official firm Producer's in void "CE", by the official product Protocol "CE" with mandatory prevency of known serious user risk, by the contents " The Certification testing of new Users -CE, Preoviders Health care and medical staff" by the safety medical processing of implanting THA from the knowledge's and skills the firm B. Braun Germany for set THA Bicontact S Noncemented!

No Claims or civic Protests are in Czech Republic acceptable in today's Justice. CZ, because many Patient CZ as Victims CZ should dying, any of them earlier with medical in forced illegal medical care, but always there are the accepted Victims CZ coded constant, Unique and false "LEGE ARTIS CZ"! My Death is irrelevant for Czech Republic today's, despite I am able to evidence by the usage the Artificial Intelligence the Millions of fatal technical medical similar mistakes daily from the databases EHRs., maybe I will inspirate Medicine US for efficiency prevency and with more respects to my Utility model 21532 CZ 2010 "Statistical Retrieval and Search of sufficient information to reuse information for repeated strategic decision making with risks and computer support - of course with minimize increases of entropy in informal long being Channel. There are namely sure - the each needless surgery, each of technical illegal medical mistakes, each of needless Patient risk to shorten his "Well being" or by biostatistics predicted Shorten Patient Life. There are always fatal medical mistakes contrary the scientic arguments of Cybernetics, Biostatistics, Biomechanics, Geometry 3D, Managing, archiving the Health documentation, statistic modelling, creature of dynamic Patient Clusters for Data mining, etc.

The legal usage the new Medical Devices under level of Knowledge's, skills in rules of finishing Clinic practical users medical Tests and contrary requirements of Health prevency known risks by definition in Protocols "CE" for Medical Devices with a needless worse Patient Risks, needles injuring, Patient Death.... there are absurd illegal habits of today's Providers 


\section{Orthopedics and Rheumatology Open Access Journal (OROAJ)}

Health care CZ and medical staff with false Diploma about "The Certification of educated and skills of new Users CZ for Medical Device XXXX"!

The Criminal Police CZ are sleeping to responsibilities of Providers Health care CZ, I am needless dying experienced scientist CZ and State investigator Health and Safety - after the Complot of my medical Culprits, including the medical staff of the Knowing Medical Institute, with false judicial providing of civic Court trial No 36C 181/2009 contrary the Constitutional Human Rights of Patients CZ. with the false Medical Court Message from the Central Army Hospital Prague CZ, with the false derived the followed Judgement No 36C 181/2009-221. Since the September 24, 2012 without regards to Criminal evidences offered to Court trial of the Plaintiff of the previous wisdom false repeated Court Medical Message with false arguments contrary principles Biomechanics, Criminal Traceing, Criminal Anthropology, contrary principles Geometry 3D, Technician Radiology by Diagnostics of the Crash "Fausse route stem" metalic stem from set THA in conflicts with Firm installing radiologic masks on each of RTG images, etc.

The Criminalist casual Analyse I sent to hands of all Participants the Court Trial Regional Court Prague No 36 C $186 / 2009$ - by written in the form of recommended official letter since date July 17, 2012, parallel for all Participants Court trial - when the official Court dealing was realised till September 17, 2012 - But the all Participants denied the Criminal facts about causes of my heavy injuring in surgery hall since date November 13, 2007 to begin the next public Execution of my individual human Rights to live, my human Rights to be a respectable Participant in the justified legal Court Trial, with the Truth Criminal Technical evidences only about my casual mortal needless Patient orthopaedic injuring in The Regional Hospital Mladá Boleslav on Orthopaedic Clinic in date November 13, 2007 !

There were 4 month in first posttraumatic time to Neurochirurgical reconstruction my nervus Ischidici in the right leg - but No Orthopaedist - Traumatolog sent me to timing next rescued Health neurochirurgical care they weren't enough oriented in Level of medical cooperating branches, I am long life needless crippled, despite such advise could be created and computerised by the usage Artificial Intelligence always in similar Patient polytraumatic situation!

While times in Case of Crashes a like hood Airplanes in US or in Candadian Airspaces followed the carefully Criminal Analyses of State supervisions of causes and consequents of each tragic elementary Crashes of Passengers - but the Mass needless yearly mortalities of thousands Patient CZ, OECD are never in the Subject of Criminal Analyses CZ, OECD in technical false medical workflow - nor at least for the random Samples of Mass yearly impaired Victims as Patients CZ, OECD. I am beginning to work on this scientic views despite the first Price is my in forced Criminal Patient Death CZ - but you could continue in my Ideas in US Medicine and in OECD too! There are extremal easy to find Mass repeated fatal technical medical mistakes, but the doctors are satisfied!

There are world scientic shame to mixed illegal technical medical partial mistakes with other medical activities and to argument there are resulting the Legal Medical Processes CZ with Sum needless dying Patient CZ, again as the Victim CZ "Lege artis CZ"!. Don't repeat such horrible Medical Mistakes in US, in OECD, despite I am needless dying "LEGE ARTIS CZ" by the Court Judgement CZ. It is a wisdom Criminal Mord of Patient CZ by Health care - by the wisdom Assistance by the judicial Court Execution - including The Knowing Medical Institute The Central Army Hospital Prague CZ, it should be stopped and with a new evaluating - in the renewed justified Penalty Court trials with all my Culprits - all Persons and all false working Organisations, all Authors of false medical judicial testimonies!

No. it is only a romantic Dream CZ about scientic and legal multilateral scientic Truth in Court Trial Processing CZ. My Culprits are morbid smiling to my in forced preliminary probable Patient Death after false processing in Orthopady CZ and they are still smiling by constant growing my Health orthopaedic complication and casual mortal risks with Origin primordial Absence of mandatory Clinic Plan of my orthopaedic THA surgery since date November 13, 2007, by Loss of most part of my post operational rest of Locomotion ability, false skeletal balances, "Cock limbing" by in forced the next Reoperation THA after 17 days, with repeating the full Brain Anesthesy, by in forced me lifelong full plegia of the right Underknie (Nervus Ischiadici in both Portions) when the duration the depressed the Nervus with Blooding and with following blood oedem caused 17 days of the destructured tight musculature of the metallic false post operational position of the Stem from set "THA" by Crash "Fausse route in the Hall" since date November 13, 2007 ), they are always smiling for my many times yearly too often frequently dangerous fallen with $8 x$ probable worse risk to arise a new femoral proximal breaking the femoral Neck after risky fallen, they are smiling with often slightly destructed my futtock shroud after some happened fallen yearly, they are smiling so as by the in forced me the needless additional Leukemia B-CLL after the redundant repeated many needless extremal strong RTG ionisation my whole body in the Knowing Medical Institutes in January 2012 - without usage any recommended protective patient equipment to covered Blood creating life system, my fertility organs, my abdomen, etc. - all and forever with in forced exwaitng Patient Death including - it will be documented Official and false as "LEGE ARTIS CZ!" in Justice.CZ, in Criminal Police CZ, in State penalty Offices CZ! Czech Republic needs no living experts in Cybernetics and Health and Safety. I am fully executed in my Human Rights to live, to be a participant of justified Coiurt trials with accepting the verified Criminal evidences of Crime Medical Acts to ignore implanting Technician requirements of EU/CZ Laws for Orthopady CZ. 
You are just a probable game Participant or a next similar threatened. Patient for clever Medical Care with risks such in a game as statistic similar the Russian Roulete since tomorrow... and you should be informed in time and very intelligible wals today's - about your practical probable Caunting Chances to live OR to die by false Diagnostics or false choice of the right individual treatments with relative frequency about $10 \%$ in each independent next Medical Decision Making about you! Maybe tomorow you will be begin pray plesdingly for your not self-evident continuing Human Life, for your Families Life - more informed about Medical habits petrified Mass technical illegal medical mistakes. Your Ambuilancy Patient visits are hard limited your motivation to live till Age $90+$ by your mental and physical well being Healthy!

Ordering placement the identified each individual step in the processing of the sequential visiting of the Russian Roulette or a like hood your Visit by the any next Physician.....1,2,3,4,5,6,7 the Probability of partial casual Phenomenon $\mathrm{Pi}=$ Semantic explanation:... you were with basal right medical defined
Diagnose and with a right medical adequated Treatments; or with the Complementary Probability of Phenomenon NON Pi - You are maybe with statistic relative frequence $10 \%$ the additional in forced medical serious next surprised Health problem, maybe you could be exwaiting more preliminary you're in forced casual Patient Death including with biostatistic predicted casual Shorten your Patient Life about many years!

By the logic aggregation of all Phenomenons' there are known the basal algorithms for complementary Phenomenon's with multiplication of frequence probabilities by repeating in steps of experiments. I was taken the Inputs of the World Health Organisation for standard relative fatal mistakes in Diagnostics and the choice of right individual Treatments are for the Medicine OECD with fatal medical mistakes with additional heavy Health injuring or casual mortal Living Problems of Patients OECD are $10 \%$ ! We could create next tabulation Relative Distributions of the Probabilities „to be Healthy yet despite your 10 Visits by the various Providers Health care, in systems Outdoor or Indoor Patient's Visit Medical Ambulancies, Clinics, Hospitals, in like hood countries OECD! (Table 1).

Table 1: The Distribution of risks for the game Russian roulette. Or by the average Patient Visits in various Medical Ambulance OECD with medical risks in decision making in Diagnostics and right choice of individual right Patient Treatments.

\begin{tabular}{|c|c|c|}
\hline $\begin{array}{c}\text { Ordering Shoots or Your Visits in Next } \\
\text { Ambulancy }\end{array}$ & Pi, You are Living, as a Wonder Till Today's & $\begin{array}{c}\text { Non Pi, You are Probable Died Yet, or with } \\
\text { Heavy Additional Healthy Complications }\end{array}$ \\
\hline 1. Shoot & 0,9 & 0,1 \\
\hline 2. Shoot & 0,81 & 0,19 \\
\hline 3. Shoot & 0,729 & 0,271 \\
\hline 4. Shoot & 0,6561 & 0,3439 \\
\hline 5. Shoot & 0,59049 & 0,40951 \\
\hline 6. Shoot & 0,531441 & 0,568559 \\
\hline 7. Shoot & 0,4782969 & 0,565328 \\
\hline 8. Shoot & 0,4304612 & 0,6125796 \\
\hline 9. Shoot & 0,3874204 & 0,6513217 \\
\hline 10. Shoot & 0,3486713 & \\
\hline
\end{tabular}

$\mathrm{Ei}=\mathrm{Pi}+\mathrm{NON} \mathrm{Pi}+\mathrm{a}$ Impossible Phenomenon $=1$

Dg. FAUSSE ROUTE STEM from the false punctuare orthopadic placement the stem in Surgeon Hall since November 13, 2017, Hospital Mladá Boleslav, Patient Antonín Cuc, put by the Knowing Medical Institute - The Central Army Hospital Prague CZ - it was been declared false again in Medical Court Message No. 36 C 181/2009-123 since March 27, 2012 - as LEGE ARTIS CZ by the false Medical Hypothese. The post operational happened fallen of the Patient despite it is absurd in Criminal Anthropology, Biomechanics, Geometry 3 D - FATAL NONSENCE! Product CE Implant BICONTACT S, no cemented stem $13 \mathrm{~mm}$, by firm B. Braun, Germany. The Fausse route was able to detect since the first sagittal RTG Image from November 16, 2007, but the Radiologist was interpreting illegal in hand and by intuitive observing only O.K. - LEGE ARTIS CZ! All Claims of the dying Patient CZ are refused by the Judge CZ, by the Criminal Police CZ too! 


\section{Your next submission with Juniper Publishers} will reach you the below assets

- Quality Editorial service

- Swift Peer Review

- Reprints availability

- E-prints Service

- Manuscript Podcast for convenient understanding

- Global attainment for your research

- Manuscript accessibility in different formats

( Pdf, E-pub, Full Text, Audio)

- Unceasing customer service

Track the below URL for one-step submission https://juniperpublishers.com/online-submission.php 